\title{
ENHANCED REFRIGERATOR WITH QUALITY AND QUANTITY MONITORING (ERQQM)
}

\author{
S.Shwetha \\ Dept. of ECE \\ KS Institute of Technology. \\ Bangalore, Karnataka, India
}

\author{
Chandana R \\ Dept. of ECE \\ KS Institute of Technology. \\ Bangalore, Karnataka, India
}

\author{
Shreyashwini V \\ Dept. of ECE \\ KS Institute of technology. \\ Bangalore, Karnataka, India
}

\begin{abstract}
The 'ENHANCED REFRIGERATOR WITH QUALITY AND QUANTITY MONITORING (ERQQM)'aims in designing a refrigerator which will monitor the quality and quantity of food kept in it and notify its users about the same. Existing systems use RFID or Barcode scanner to keep track of the stock. The existing systems are expensive. The proposed system can be embedded into a refrigerator along with sensors.

The core functionality of the ERQQM is to assess quantitatively and qualitatively the contents in the refrigerator. As a result, the user is notified every time restocking has to be done. This is done using the RFID module or the barcode scanner along with load cell, odour sensor, and temperature sensor. Further research and collection of data on the gases emitted from the deterioration of stock and also on improving efficiency is being done and can be implemented later.
\end{abstract}

Keywords - Refrigerator, Internet of things (IoT), Arduino board, Arduino IDE software, Sensors.

\section{INTRODUCTION}

A refrigerator is the most frequently used electrical appliance all over the world for food storage. Many smart refrigerator variants have been developed, but none of which has been cost effective. Some of the major developments were from Samsung and LG. These refrigerators were an unsuccessful because the consumers had seen them as an unnecessary product and due to the high cost (more than $\$ 20,000)$ and the problems solved were obscure. Electrolux's Screen fridge is equipped with a computer and touch screen built into the refrigerator door and does not consume existing storage space. This refrigerator is also connected to the Internet. Besides using the refrigerator to send e-mails or to surf the Internet, the homeowner can also use it to select, buy and order food without leaving the kitchen. The fridge will ultimately include a scanner able to read the electronic tagging found on all food and liquid packaging in the future. This way, the refrigerator can keep track of the stock of food that has been bought or to be purchased. The modern living in a fastpaced environment doesn't allow the user to keep track of the food items inside the fridge. Although efforts have been put to develop the smart refrigerator, the existing technology is still not cost effective.

The ERQQM is designed to convert any existing normal refrigerator into a smart and low-cost machine using sensors. The ERQQM notifies about the quantity and quality of stock in the refrigerator. Significance of this work would be alerting the spoilage of food, reduce wastage of food and create a healthier lifestyle for its users.

The ERQQM can be controlled by remote users, it can be turned on and off and also notifies its users about the scarcity of frequently used products using RFID. It also facilitates the ordering of scarce items by intimating (a) predefined grocery vendors through SMS or through an online portal. The load cell helps in monitoring quantity and quality. The grocery on degrading has found to be losing weight and the load cell will sense it.

\section{LITERATURE SURVEY}

We have drawn conclusions based on our survey. Earlier, the refrigerators were made smart by integrating storage with media. LG, Samsung, Electrolux and Whirlpool made refrigerators that had a TV screen, MP3 player, and touchpads embedded into them [2]. Their main objective was to make the kitchen a place of cooking and entertainment. These refrigerators were considered an unnecessary expense and failed the market. They could not monitor the quantity or quality of the stock.

In this paper [6], the authors offer us several food related data sets and they monitored the stock quantity with these data sets such as UNIMIB 2016, food-101, UNICT8899. They have a large data set which can be help keep track of the stock.

Image scanning has been used to monitor the stock and create shopping lists [7]. The installation cost is high and integration is very complex.

In the paper [8], the refrigerator monitors the stock using photodiodes with high sensitivity. This is a drawback as photodiodes might be interfered by light from an external source. The paper uses Node MCU as an interface to communicate between the refrigerator and the user. The food quantity is monitored using RFID scanner and GSM 


\section{International Journal of Engineering Applied Sciences and Technology, 2020 \\ Vol. 4, Issue 11, ISSN No. 2455-2143, Pages 128-130 \\ Published Online March 2020 in IJEAST (http://www.ijeast.com)}

technology [9]. This system is cost efficient. Quality of stock hasn't been monitored here.

\section{METHODOLOGY}

All The system comprises of sections in which the sensors are placed. It develops the solution around a concept of smart fridge equipped with an onboard processors and sensors and informs us through an application about the quantity and quality of the stock.

Light dependent Resistors (LDR) sensors, odour sensors and load cells are placed along a counter which can be used to sense the quality and quantity of contents. They can be used to detect the level of liquid stock in the containers and to sense the presence of vegetables in the refrigerator. RFID transmitter and receiver are used to monitor the shelf life of contents. Whenever the contents inside the ERQQM goes below the predetermined threshold values or are degraded in quality, or if the product is on the verge of expiry, a trigger is generated which is then transmitted in the form of message to the user and a reordering list is created and sent to a predefined vendor though SMS or an online portal.

Fig. 1 shows the proposed system block diagram.

\section{CONCLUSION}

The ERQQM module can remotely notify the user about the low contents of food items inside the refrigerator. It can also be able to remotely turn on and off the refrigerator and notify the user about scarce products via message alert and purchase of scarce items by sending a re-ordering list to the predefined vendor. The module also provides other advantages liked improved efficiency, smell detection, quality and quantity management.

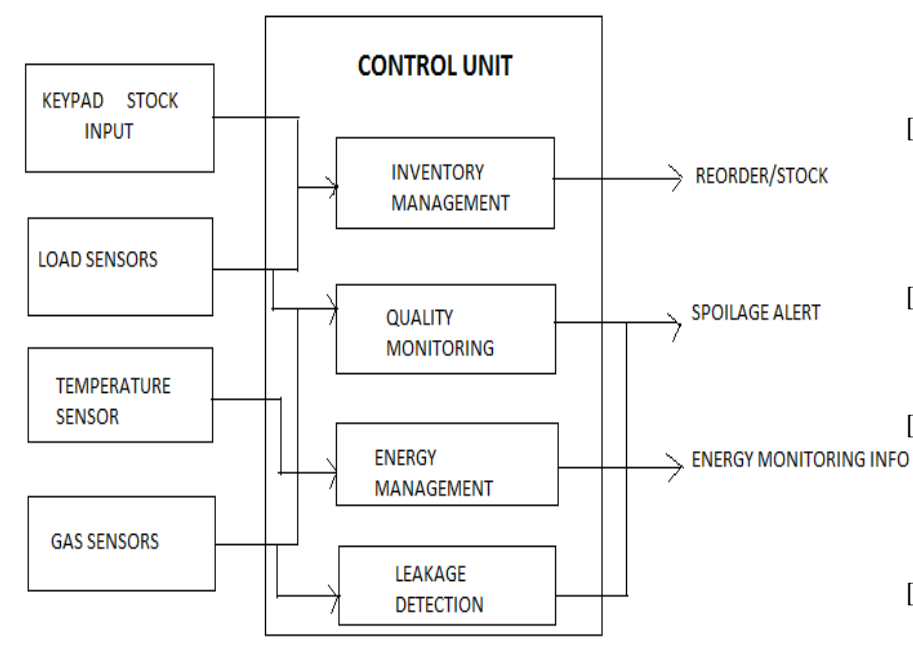

Fig. 1. The proposed system

\section{REFERENCE}

[1] Prapulla S. B., Dr. Shobha G., Journal of Multidisciplinary Engineering Science and Technology (MEST) ISSN: 3159-0040 Vol. 2 Issue 7, July - 2015.

[2] Suhuai Luo, Jesse S. Jin, and Jiaming Li.International Journal of Multimedia and Ubiquitous EngineeringVol. 4, No. 2, 'A Smart Fridge with an Ability to Enhance Health and Enable BetterNutrition' April 2009.

[3] SomayyaMadakam, R. Ramaswamy, SiddharthTripathi, Journal of Computer and Communications, 2015, 3, 164173, 'Internet of Things (IoT): A LiteratureReview' Published Online in SciRes. May 2015.

[4] Deepti Singh, Preeti Jain. International Journal of Advanced Research in Electronics and Communication Engineering (IJARECE) Volume 5, Issue 7,. 'IoTbased Smart Refrigerator System’ July- 2015.

[5] FolasadeOsisanwo, Shade Kuyoro, and OludeleAwodele, 'Internet Refrigerator- A typical Internet of Things (IoT) 3rd International Conference on Advances in Engineering Sciences \& Applied Mathematics (ICAESAM'2015) London, March 23-24, 2015.

[6] Mark Buzzelli, Federico Belotti, Raimondo Schettini, 'Recognition of Edible Vegetables and Fruits for Smart Home Appliances', 2018 IEEE 8th International Conference September 2018.

[7] Stephen Goeddel, Pasha Sadeghian, Aspen Olmsted, 'Weighing the shopping benefits of a smarter refrigerator', The 12th International Conference for Internet Technology and Secured Transactions - 2017.

[8] Matthew Edward1 , Kanisius Karyono2 , H Meidia3, 'Smart Fridge Design using NodeMCU and Home Server based on Raspberry Pi 3', 4th International Conference on New Media Studies Yogyakarta, Indonesia, November 08-10, 2017.C.S November 2017.

[9] R. Angeline1, YashKetan Patra2, Karthik Kembai3, Sangram Mandal4, 'SMART FRIDGE - A 24/7 Grocery Reminder', International Research Journal of Engineering and Technology October, 2018.

[10] Ridden, P. (2017). LG lauches first Smart-Grid appliance: The Smart Fridge, Retrieved Mar. 27, 2017 from http://newatlas.com/lg-smartfridge/18502/

[11] Food and Agriculture Organization of the United Nations. (2017). Food Wastage Footprint: Impacts on natural resources. Retrieved Mar., 2017, from http://www.fao.org/docrep/018/i3347e/i3347e.pdf

[12] Prof. M. K. Sangole, Bhushan S. Nasikkar, Dhananjay V. Kulkarni, Gitesh K. Kakuste, "Smart Refrigerator Using Internet of Things (IOT)", Sangole K. M. et al.; International Journal of Advance Research, Ideas and Innovations in Technology. Volume3, Issue1,2017 
[13] Likitha R.V, R.Nagashree, Shruti P, "IoT Smart Fridge”, International Journal of Advanced Research in Electronics and Communication Engineering (IJARECE) Volume 5, Issue 4, May 2016

[14] Perumal T,Sulaiman,Musthapa,Shahi A, "Proactive Architecture for Internet of Things (IoTs)",published in2014 IEEE 3rd Global Conference on Consumer Electronics (GCCE), 7-10 Oct. 2014

[15] Rothensee M., User acceptance of the intelligent fridge: empirical results from a simulation, The Internet of Things, 2008, pp. 123-139. 